\title{
Chapter 20 \\ Analysing the Risks Posed by Biological Invasions to South Africa
}

\author{
Sabrina Kumschick $\mathbb{D}^{D}$, Llewellyn C. Foxcroft $\mathbb{D}$, and John R. Wilson
}

\begin{abstract}
Risk analysis is an important decision-support tool for the management of biological invasions. South Africa, as a signatory to international agreements, has enacted legislation requiring risk analyses to be conducted if trade is to be restricted or regulated and if alien species are to be introduced. In this chapter, we outline the various needs for risk analyses for biological invasions in South Africa, summarise the current status, and make recommendations for a way forward. In particular, we highlight the need to move away from approaches that are purely based on expert opinion or entirely reactive, and propose a new system and process which includes the use of a structured risk analysis framework with clear guidelines to avoid expert bias. We highlight the need to assess risk, consider risk management options (including benefits), and to develop clear recommendations. The proposed process also involves the review of recommendations by an independent panel. We further note that the effectiveness of such approaches will be defined by their transparency, their accuracy, how feasible they are to implement in practice, and the trust that people have in the system.
\end{abstract}

\footnotetext{
S. Kumschick $(\bowtie) \cdot$ J. R. Wilson

Centre for Invasion Biology, Department of Botany and Zoology, Stellenbosch University, Stellenbosch, South Africa

South African National Biodiversity Institute, Kirstenbosch Research Centre, Cape Town, South Africa

e-mail: sabrina.kumschick@gmail.com

L. C. Foxcroft

Conservation Services, South African National Parks, Skukuza, South Africa

Centre for Invasion Biology, Department of Botany and Zoology, Stellenbosch University, Stellenbosch, South Africa

B. W. van Wilgen et al. (eds.), Biological Invasions in South Africa, Invading

Nature - Springer Series in Invasion Ecology 14,

https://doi.org/10.1007/978-3-030-32394-3_20
} 


\subsection{Risk Analysis for Biological Invasions}

Frameworks for the management and regulation of alien species and associated processes have been developed all over the world to deal with undesirable consequences and to mitigate future impacts of species introduced outside of their native ranges. Risk analysis is a formal, evidence-based process to analyse the risk of a particular hazard to a certain area or situation. A hazard can be an event or phenomenon, like the increase of temperature globally or the pollution of a river with chemicals. A hazard can also be more specific, like the introduction of an alien species to a new area. This chapter reviews what has been done in South Africa in the context of international best practice, and outlines a proposed way forward.

In general terms, risk analysis is the combination of hazard identification, risk assessment, risk management and risk communication (Fig. 20.1). Biological invasions present various hazards that can be broadly grouped in terms of species, pathways, and areas. If the hazard is the alien species itself, risk assessment includes the likelihood of a particular species being introduced, establishing and spreading in an area, and the consequences (negative impacts) thereof; risk management focuses on management options available for the species, the ease of management more broadly, and people's perceptions and uses of the species that could lead to conflicts of interest around its control (Branquart et al. 2016). For pathway risk assessment, the likelihood and consequences of the pathway or vector bringing in harmful alien species is assessed (in this case, risk is often proportional to the number of harmful alien species introduced along a pathway, i.e. the colonisation pressure); and risk management focuses on interventions to make the pathways "cleaner" (e.g. the Ballast Water Convention; IMO 2004). Lastly, area-based risk assessments examine the suite of alien species in a certain area and the vulnerability of the area itself to

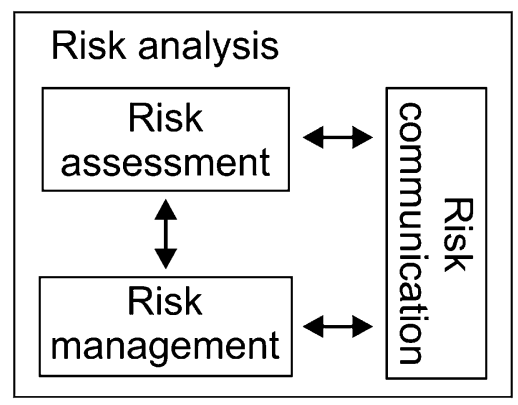

Fig. 20.1 The components of risk analysis. Hazard identification frames the problem that is being addressed (with respect to biological invasions this is often in terms of pathways, species, or areasnot shown in the figure). Risk assessment focuses on the likelihood and consequences of the hazard occurring. Risk management considers ways to mitigate the risks while maintaining any benefits. Risk communication aims to ensure effective communication and sharing of relevant information between stakeholders and assessors during the process of risk assessment and management, both to improve the information available for the risk analysis and to try to ensure that everyone ultimately agrees to abide by the outcome of the process 
invasion, to distinguish high from low risk areas; and risk management efforts aim both to reduce the total level of invasion in the area and to limit the potential for all pathways to bring in new species. Since alien species generally affect a wide variety of stakeholders and are socially complex rather than clearly defined scientific problems (Woodford et al. 2016), communication with stakeholders is key throughout the process. Such communication needs to be a two-way process which aims to inform people about the outcomes of the analysis (risk communication), but also ensures stakeholders' knowledge, opinions, and concerns are considered during the risk assessment and risk management planning.

Besides the assessment of different hazards, risk analyses can also focus on different stages in the invasion process (Blackburn et al. 2011). One of the most prominent distinctions is between pre- and post-border analyses. It is often much more cost-effective to prevent an invasion from happening than to mitigate the harm or try to eradicate a species once it has established-pre-border risk analyses can help to make decisions about whether or not to allow the import of a new species, based on risk to the recipient environment. For species that are already present, we need ways to assess which to regulate and manage post-border. The main distinctions between pre- and post-border analyses are therefore: (1) the need for pre-border analyses to include the likelihood of arrival and introduction into the country; and (2) the need for post-border analyses to include risk management considerations focussing on reducing the negative impacts of invasions while maintaining benefits, and reaching agreement between stakeholders that might hold opposing entrenched positions.

Risk analysis methods ideally have a few key qualities that make them useful for helping to make management decisions including that they should be transparent, accurate, realistic, evidence-based, and free of biases as far as possible. Transparency ensures that decisions are traceable and the rationale behind them is clear. Accuracy is needed so that resources are not wasted on managing benign species, or so that potentially harmful species can be prevented from becoming problematic. Risk analysis also requires resources to implement, including financial and human capital (i.e. skilled practitioners). Given the inherent biases any assessor may have (e.g. Montibeller and Von Winterfeldt 2015) it is also important that such analyses are based on sound evidence. Furthermore, group assessments and independent review panels can minimise biases by a single assessor. Explicit guidance documents and training of assessors in the principles and methods of risk analysis can further improve the process and reduce assessor bias rooted in a different understanding of the questions asked. A group of European scientists developed a minimum set of 14 standards for risk assessment to aid their implementation for the EU Regulation on invasive alien species (1143/2014) (Roy et al. 2018), many of which overlap with what is discussed in this paragraph, and a few of which are specific to the requirements of EU regulation (like the assessment of impact on ecosystem services and effects of future climate change). But these standards are also useful in a South African context and have largely been followed in what is suggested here. 


\subsubsection{Risk Assessment}

Many tools have been developed to assess the risk of biological invasions, but most focus on specific species as the hazard (Kumschick and Richardson 2013). Such tools typically cover a variety of aspects related to the risks posed by a species, which includes transport, establishment, abundance, spread, and impact (Leung et al. 2012). However, there are also many tools that cover or assess only a specific part of the risk of a species and which are often mistakenly put under the umbrella of "risk assessments". For example, much effort has been put into standardising the way we quantify impacts, and many recent developments were made around impact assessment tools (e.g. Blackburn et al. 2014; Bacher et al. 2018; Zengeya et al. 2020, Chap. 17). Similarly, species distribution models and climate matching tools are improving the way we can assess and map a species' climatically suitable area in a new range (see Wilson et al. 2020, Sect. 13.5, Chap. 13). Van Wilgen et al. (2009), for example, present climate suitability matches for amphibians and reptiles that can improve the way we assess risks for this group. In combination with other tools, climate suitability models and impact assessments can improve the assessment and analysis of risks of biological invasions in a transparent, standardised, and repeatable manner. However, by definition, a risk assessment needs to cover both the likelihood of the hazard occurring (i.e. the invasion process) as well as its consequences (i.e. the negative impacts).

Despite the aspects of risk to be covered being rather straightforward, there are many ways in which these can be assessed in practice. Several approaches to risk assessment have been suggested, including the trait-scoring, statistical, decisiontree, rapid screening, mechanistic, and detailed approach (Keller and Kumschick 2017). Each of these has its own benefits and weaknesses and is based on different premises:

Trait Scoring This assumes that species with specific traits have a higher chance of becoming invasive, and of having higher impacts. In other words, the more "invasive traits" a species has, the higher the risk it poses. This is the most common approach used to date, including in the Australian Weed Risk Assessment model (AWRA; Pheloung et al. 1999), which was developed as a pre-border tool to screen alien plants to be introduced to Australia. The AWRA has been used around the world and modified for different taxonomic groups including fish and freshwater invertebrates (Copp et al. 2005; Tricarico et al. 2010; see Appendix in Kumschick and Richardson 2013). This approach of assessing risk requires information about the taxon as alien and what makes some species more successful than others. It also assumes that the main contributor to invasion success is inherent to the introduced species' traits, and it is generally limited to a taxonomic group with comparable traits.

Statistical Approach The statistical approach is very similar to trait-scoring insofar as it uses traits of species to predict the potential for invasion and causing harm (Keller and Kumschick 2017). In the trait-scoring approach (seemingly) important traits are collated and rated by experts only. In the statistical approach the list of traits is refined using statistical or machine learning algorithms. These algorithms find 
patterns in the data and include only those traits that contribute to invasion success, as opposed to all traits considered important by experts. For example, for alien cacti it was found that native range size is a predictor of both impact and invasiveness in South Africa (Novoa et al. 2016a). The statistical approach can take into account interactions between traits and lead to much simpler tools than trait-scoring, but the underlying methods and mechanisms are not always easily understood and therefore less likely to be supported by managers and policy-makers (Keller and Kumschick 2017). Furthermore, due to the models including a very limited number of variables, no conclusion can be reached if data for any of the few selected variables is lacking.

Decision Trees These can be a subset of the statistical approach, but also be based on traits considered as important by experts. Similar issues therefore arise in this approach, which comprises of several questions of which each answer leads either to another question or a decision regarding a species' risk. If the answer to any question is not known, no decision can be reached, or tenuous assumptions are made. For that reason, this approach has not been used extensively. However, Tucker and Richardson (1995) suggested a decision tree approach to assess risks of tree invasions to the Fynbos Biome.

Rapid Screening The rapid screening approach can use elements of the previous three approaches, with the focus on a quick assessment of often a large number of species where little information is available. Rapid screening can be used as a standalone risk assessment, to prioritise species for more detailed risk analysis or to create watch lists. Faulkner et al. (2014) applied a rapid screening tool to almost 400 species to create a watch list of alien species for South Africa. Their tool included only three aspects: (1) the invasiveness of the species elsewhere, (2) climate match, and (3) tourism and trade data as a proxy for propagule pressure.

Mechanistic Approach The mechanistic approach is not based on traits per se, but it follows a species through the invasion process and assesses the likelihood that it will cross certain barriers (e.g. those proposed by based on Blackburn et al. 2011), and whether it has the potential to have an impact. For example, if a species is unlikely to find suitable climatic conditions and habitats in a new region, it would be unlikely to establish and subsequently become invasive, which can reduce its risk despite potential impacts. Such an approach is implemented in Belgium (D'hondt et al. 2015).

Detailed Approach The detailed approach, as the name suggests, requires a substantial amount of data on the alien species' ecology, biology and behaviour, as well as the recipient environment and the interaction between all these factors. It often requires additional research to fill knowledge gaps, which may include interviews with experts. Since it also includes management considerations and stakeholder perceptions, it resembles more closely a risk analysis approach. It has been used in Canada to assess risks of the highly contentious Asian carp species (Mandrak and Cudmore 2004).

Which approach is most useful depends on the circumstances and purpose. For example, rapid screening is quick and easy. However, results of such assessments provide limited knowledge on the mechanisms of invasion and expected behaviours 
of a species under specific circumstances as the underlying assumptions are often not explicit. This can be problematic for species with no previous history of introduction outside of their native range (no "invasion history"). Trade-offs between the optimal investment and the optimal outcome need to be made when selecting an approach for a risk assessment tool. Furthermore, the amount of knowledge available on a taxon can limit the use of certain approaches. The statistical approach requires the input of a substantial amount of data to train the model — without adequate knowledge about the taxon and its behaviour as an invader, such models cannot be developed. Furthermore, the final model requires data on only a few variables, which increases the likelihood of this information not being available for some species. This emphasises the need for a risk assessment tool to accommodate situations where information on a species to be assessed is scarce or lacking.

Many tools approach this by applying the precautionary principle-if no data are available on a species or a certain situation, preventing informed decision-making on the risks involved, the species is by default deemed to be a high risk (e.g. Nentwig et al. 2016). This principle is common practice and also anchored in international agreements. For example, in the management of alien species, the IUCN (2000) states that "unless there is a reasonable likelihood that an introduction will be harmless, it should be treated as likely to be harmful".

\subsubsection{Risk Management}

To reach sensible and effective management decisions, risk management considerations are fundamental. Ignoring management feasibility, benefits of the taxon, or potential conflicts between stakeholders, has been shown to lead to unsuccessful and wasteful management decisions (e.g. van Wilgen and Richardson 2012). The distinction between whether, as opposed to how, to regulate and manage a species relies on estimating the risks it poses to the recipient environment and economy. For taxa that are not yet present in an area, and for which decisions on importation are required, this can be a relatively straightforward process: if the species poses a high risk its importation should not be allowed, but if it poses a low risk the species could be considered safe for import (e.g. Keller and Kumschick 2017). However, decisions regarding taxa that are already present in an area, and in use for various purposes, cannot solely rely on estimates of the risks they pose, but also depend on management options available for the species. For example, many trees were introduced into South Africa for forestry. Even though many of them threaten native biodiversity, management decisions need to take into account the costs of management, the techniques and tools available, as well as the species life-history traits (Wilson et al. 2011; Richardson et al. 2015). Further, management does not happen in isolation from the rest of society; social perceptions and benefits need to be assessed and accounted for (e.g. van Wilgen and Richardson 2012; Zengeya et al. 2017; see Shackleton et al. 2020, Chap. 24). Unlike in the risk assessment where clear answers and probabilities are often provided to determine the level of risk, the inclusion of benefits is dependent on the agendas of various role players, priorities of 
decision makers, and the influence of key stakeholders (e.g. Kumschick et al. 2012; Woodford et al. 2017). To keep the process transparent, provision needs to be made to outline how the inclusion of benefits influences the management decisions, and which benefits are included.

Once a risk has been identified and assessed, and the species is regarded as of concern (i.e. high risk), one needs to consider what can be done to manage the risk (Fig. 20.2). For species already present in an area this will often require a detailed evaluation of management options, the development of management plans and

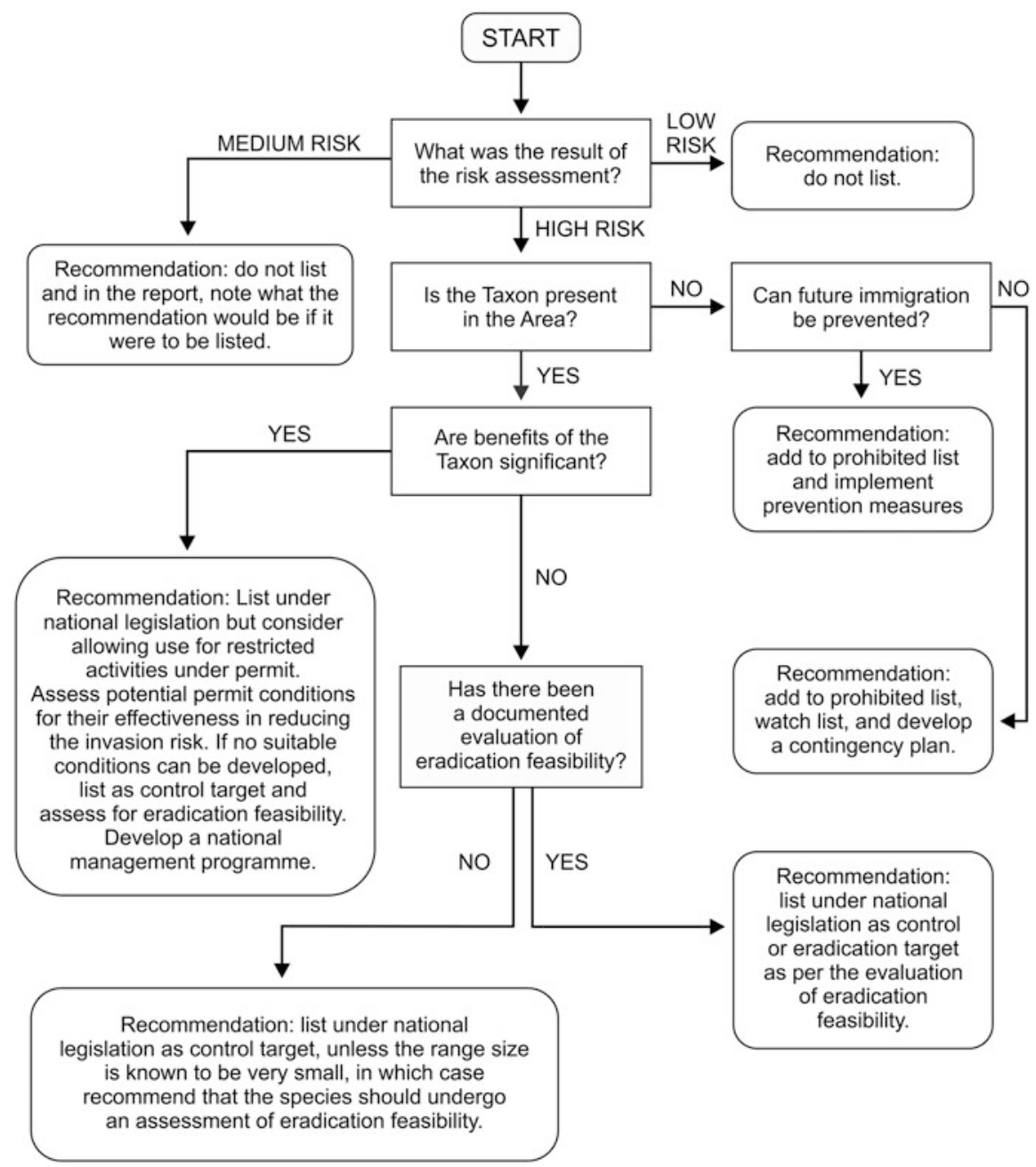

Fig. 20.2 The proposed process outlining the steps to develop recommendations for the listing of alien species under national legislation in South Africa. Reproduced from Kumschick et al. (2018) with permission 
financial resources, and a process of prioritisation of potential interventions, including considerations related to the funds available to put the management plan into action (Wilson et al. 2017). Such detailed assessments are generally beyond the scope of risk analyses which are mostly desktop-based (but see example of biological control release applications below). However, some basic management considerations need to be taken into account that allow for a broad classification of how to treat a certain risk.

Risk management is generally more open-ended than the risk assessment, but needs to be documented in detail to assure that decisions are transparent and can be revisited when information becomes available. Risk management can include parameters like socio-economic and environmental benefits, the feasibility of stopping future immigration of a risky species, and basic considerations regarding eradication feasibility (e.g. Panetta and Timmins 2004; Wilson et al. 2017). Renteria et al. (2017), for example, suggested a rapid scheme for prioritisation of alien species in South Africa for eradication, using information on the species' distribution and "eradication feasibility syndromes". While such simple desktop studies are useful to flag species for further evaluation, they are not sufficient to determine whether a species is a suitable eradication target. In practice, eradication feasibility depends heavily on the biological (e.g. location of individuals, detectability, availability of effective control methods) and administrative context (e.g. funds available, and a dedicated and persistent leader and team).

\subsubsection{Risk Communication}

Once the level of risk has been determined and options for management and benefits evaluated, it is crucial to clearly communicate the outcomes of the analysis to stakeholders, including the general public, policy-makers and traders of the alien species. There are two important requirements for risk communication. Firstly, stakeholders must be engaged during the risk analysis, both for assessors to obtain information on the hazard, and to gain the support of stakeholders (e.g. Novoa et al. $2015,2016 \mathrm{~b})$. There are often formal regulatory processes of stakeholder engagement. For example, before the promulgation of new regulations in South Africa, they are published for public comment, whereafter the comments needed to be addressed or acknowledged. In contentious cases, an independent scientific assessment might be needed (Scholes et al. 2017), but if conflicts are to be avoided, engagement should happen from the outset of the process.

Secondly, risk communication is important for providing stakeholders with sufficient information to understand the recommendations. Stakeholders need to be in a position to know under which circumstances decisions would be altered, for example, how new information or changing practices would influence risk. Therefore, communication needs to be simple enough to ensure understanding, but simultaneously enough information needs to be provided to underpin the decision. Decisions are often only successful and implementable if stakeholders understand the risks associated with the taxon. To gain the support from the general public and financial 
institutions (e.g. government departments), engagement and clear communication regarding risks is crucial. In practice, part of risk communication consists of clearly documenting the hazard, the circumstances of the assessment (including the area of assessment), and the results of the assessment, in an easily understandable manner. An easy-to-digest summary sheet including the main findings of each section (risk assessment and management), including short descriptions of the hazard (e.g. the alien species), pathways, impacts, management options, and benefits can serve this purpose.

\subsection{Risk Analysis in South Africa}

Various tools have been developed for use specifically in the South African context. Tucker and Richardson (1995) were amongst the pioneers in risk assessments for biological invasions. They developed a tool to assess the risks that woody plants pose to the Fynbos Biome, which requires information on the alien species, the region of origin, and various details specific to the Fynbos Biome, for example tolerance to fires. This approach is a combination of a trait-based scoring approach and a decision tree, and allowance is made for the lack of data on some traits or aspects. Due to the very specific focus of the scheme (the Fynbos Biome) it is most likely not applicable to a wider geographic range or different habitats, and it is limited to assessing woody plants. Similarly, other studies developing or applying risk assessments and analysis

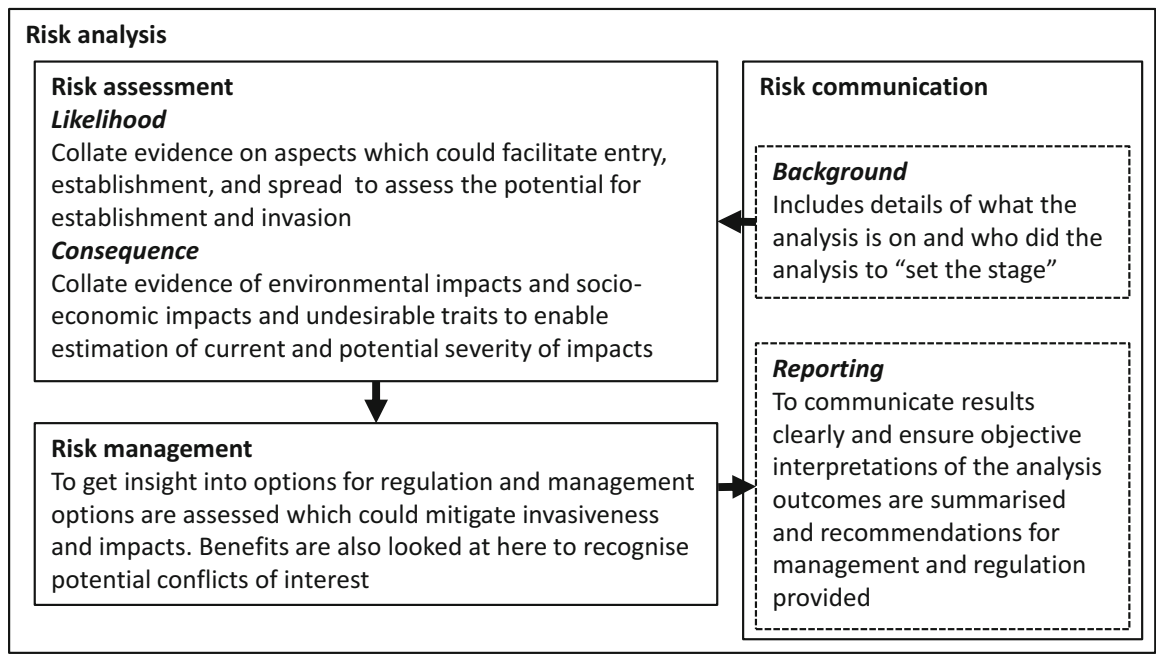

Fig. 20.3 Aspects of risk to be considered for the listing and regulation of alien species under national legislation in South Africa divided into risk assessment, risk management and risk communication based on a standard framework for risk analysis. The process suggested for risk management is shown in Fig. 20.2 
in a South African context have been rather limited in scope. For example, van Wilgen et al. (2008) called for the use of risk assessments for the herpetofauna present in South Africa, mainly introduced through the pet trade. Alien fish have been extensively assessed for their risks in South Africa (Ellender and Weyl 2014; Marr et al. 2017), also necessitated by the conflicts between conservationists and recreational anglers (see Weyl et al. 2020, Chap. 6). An exception to this is the 'watch list' approach outlined above (Faulkner et al. 2014), which is applicable in any given region and can rapidly assess a wide variety of taxonomic groups. Most recently, we developed a risk analysis framework to underpin the regulation of alien taxa and aid management decisions (Kumschick et al. 2018). It is applicable to any taxonomic group and can be used pre- and post-border.

The need for risk analyses on biological invasions has been formally adopted in South African legislation (Box 20.1). The legislation outlines actions related to alien species that need risk analyses to be completed. This includes permits for the importation of new alien species into the country and to carry out restricted activities involving some listed species, the listing of alien species under national legislation (Fig. 20.3), and the introduction and subsequent release of alien species for biological control (see Hill et al. 2020, Chap. 19). For all these issues, processes are being instituted and frameworks developed in South Africa, which need to be followed to carry out the respective activities. In Table 20.1, we summarise the legislative needs for risk analysis in South Africa, how they are currently implemented, and provide recommendations for the future (for further details see the discussion below).

\section{Box 20.1 Key International and South African Legislation Pertaining to the Risk Analysis of Biological Invasions}

International agreements under the World Trade Organisation (WTO) require the assessment of risks before certain activities involving an alien taxon, especially trade, can be restricted, or before a new taxon should be allowed for import. These agreements recognise the standards set by the International Plant Protection Convention (IPPC; FAO 1996) and the World Organisation for Animal Health (OIE 2011). The assessment of the risk that a species poses allows for the distinction between potentially harmful and benign taxa. However, risk analysis additionally includes considerations regarding whether and how these risks can be managed (Convention on Biological Diversity 2002).

These international standards and agreements which South Africa is part of are complemented by legal obligations which need to be considered and followed where risk analysis is required. Specifically, the National Environmental Management: Biodiversity Act (NEM:BA, Act 10 of 2004) Alien and Invasive Species Regulations (in short, NEM:BA A\&IS Regulations; Department of Environmental Affairs 2014) outline the necessary content of risk analyses for the application of permits, including for import and restricted activities. 


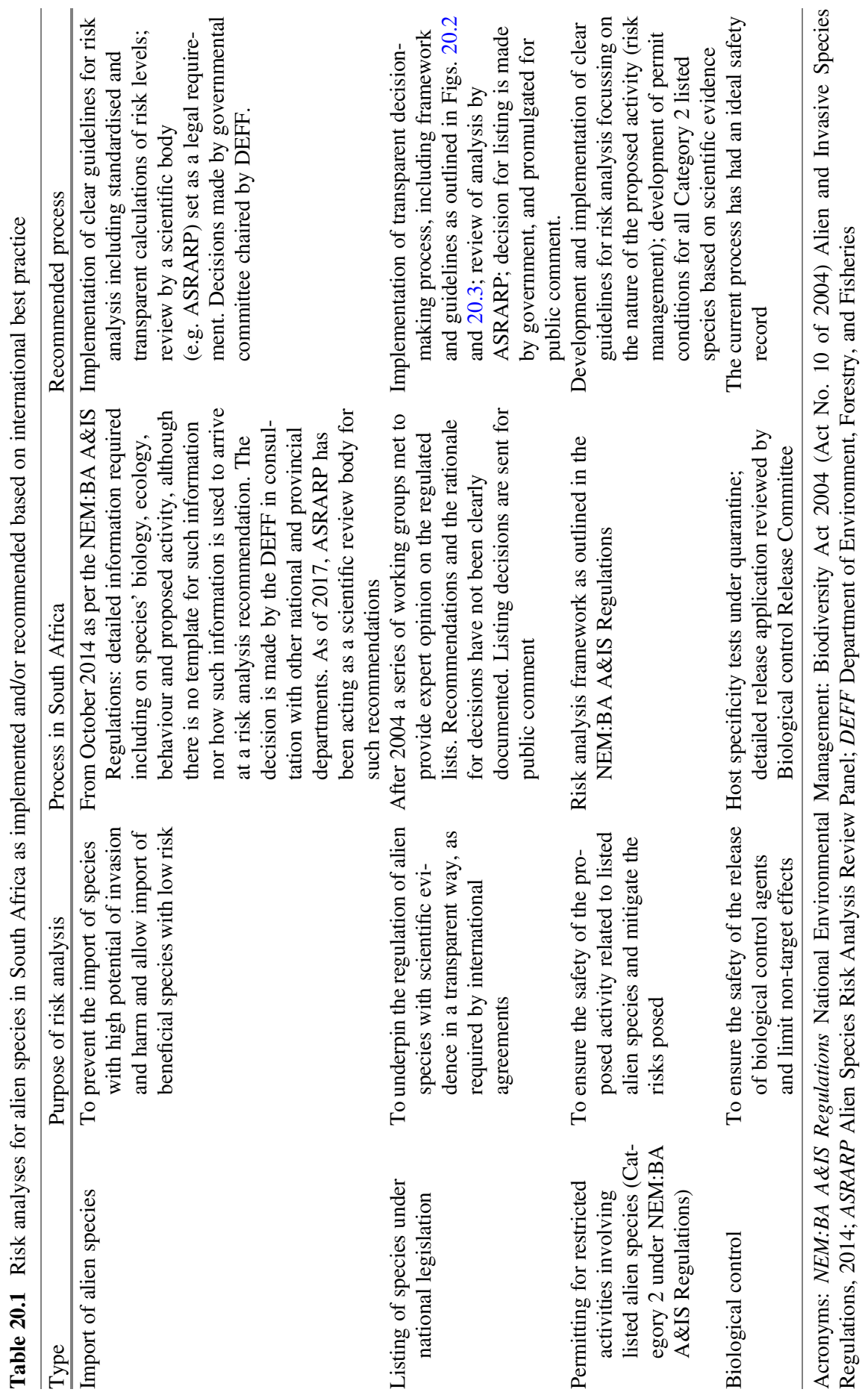




\subsubsection{Import of Alien Species}

Several government departments administer import applications for alien species; on a national level those are the Department of Environment, Forestry, and Fisheries (DEFF) and the Department of Agriculture, Land Reform and Rural Development (DALRRD) mainly concerning new introductions into the country. For many other introductions of alien species and species new to a province, provincial departments are still largely responsible for the reviewing of import applications to introduce species from outside the country. They generally need to adhere to provincial legislation, but the processes followed vary significantly between provinces and taxa. Furthermore, they depend on the expertise available in the respective departments, and no consistent frameworks are followed to guide decision-making. In the following paragraphs, we mainly focus on the import of new alien species.

DALRRD (through South Africa's National Plant Protection Organisation, NPPOZA), is mandated to prevent the introduction, establishment and spread of alien pest or disease species on plants and plant products. DALRRD conducts pre-border risk analysis for agricultural species imported into South Africa. These analyses have a focus both on minimising the risks of introducing pathogens or pests on imported species and on the risks of the species themselves becoming invasive. The responsibility of DALRRD is to reduce risks of agriculture, but in the absence of other processes before the promulgation of the NEM:BA A\&IS Regulations (see van Wilgen et al. 2020, Chap. 1, Box 1.1), DALRRD have issued permits for new introductions of non-agricultural alien species as well. This has not been sufficient to address all of the environmental risks associated with the introduction of new species, and the minimum standards for accepting introductions has historically been set differently for different organisms introduced for different purposes.

To address this, the NEM:BA A\&IS Regulations were developed and DEFF mandated to issue permits for alien species not yet legally present in the country (i.e. new introductions) (Department of Environmental Affairs 2014). Every application for the import of a species not yet present in a country needs to be accompanied by a risk analysis according to international agreements (Box 20.1). The NEM:BA A\&IS Regulations have since August 2014 outlined the information required for risk analyses accompanying import applications for the introduction of new species into South Africa (note these are currently termed "risk assessments" in the regulations, but are actually "risk analyses" as per the definitions in this chapter and in line with the international naming standards in Fig. 20.1). The requirements include information on the species to be imported, its taxonomy, biology and ecology, aspects linked to the likelihood of invasion like invasion history elsewhere, and traits linked to impact potential. This list includes several aspects that have been shown to be linked to invasion success and impact. Furthermore, it includes specific information regarding the planned activity in South Africa and measures proposed to manage the risks, which can be grouped under risk management. These risk analyses are the responsibility of applicants who wish to import new alien species, and the minimum requirements for assessors qualifications are specified in the NEM:BA A\&IS Regulations, which makes 
the quality of analyses rather heterogeneous. Furthermore, while the regulations require detailed information on the biology and ecology of the species, the region and circumstances of its introduction and other relevant factors, they do not provide guidance on how to reach conclusions on the species' risk based on that information, or how to format the analysis (i.e. it is not actually a framework for risk analysis). Given the lack of clear guidelines on how to assess and weight each aspect, and how to reach a conclusion on the magnitude of risk, it is difficult to defend the accuracy and consistency when using this approach (Keller and Kumschick 2017). Further disadvantages of this approach are that it is time and resource-consuming.

To assist applicants for import permits to develop risk analyses and to render the decision-making process more transparent, a framework and guidelines for risk analysis have been developed-the Risk Analysis for Alien Taxa Framework (RAAT; Kumschick et al. 2018). The framework is based on international bestpractice, and the guidelines cover most aspects related to the risk of alien species as outlined in the framework provided in the NEM:BA A\&IS Regulations; information on the intended activities related to the permit application would need to be outlined separately. RAAT consist of 23-29 detailed questions. Answers to questions are given as scenarios to reduce assessor bias, and calculations provided to achieve risk levels (low, medium or high). The framework includes all aspects of risk as described in Fig. 20.3. In many developing countries like South Africa, decisions need to be made with limited funds and expertise available (see also Soliman et al. 2016 for southeast Asia). Even though RAAT can take several days to complete, it is less labour-intensive than collecting all the detailed information as outlined in the NEM:BA A\&IS Regulations. Furthermore, conclusions regarding risk levels are less subjective as answer levels and calculations are outlined in detail. These guidelines are, however, not currently implemented for import applications (but see below for listing of species under the NEM:BA A\&IS Regulations).

To support the DEFF in making decisions concerning the risks of biological invasions, the South African Alien Species Risk Analysis Review Panel (ASRARP) was formed. ASRARP is tasked with reviewing risk analyses attached to import applications to ensure they are scientifically robust and take into account the best available evidence, as well as risk analyses underpinning the listing of species under national legislation (see below and Fig. 20.4). ASRARP is an independent body (run through the South African National Biodiversity Institute) that incorporates scientists and taxon experts. It provides recommendations as to the validity and completeness of the information provided in the analysis, as well as recommendations regarding the outcomes of the application (i.e. whether to import and/or regulate a species). Recommendations are submitted to DEFF who then decide whether to grant the import permit (Fig. 20.4). 


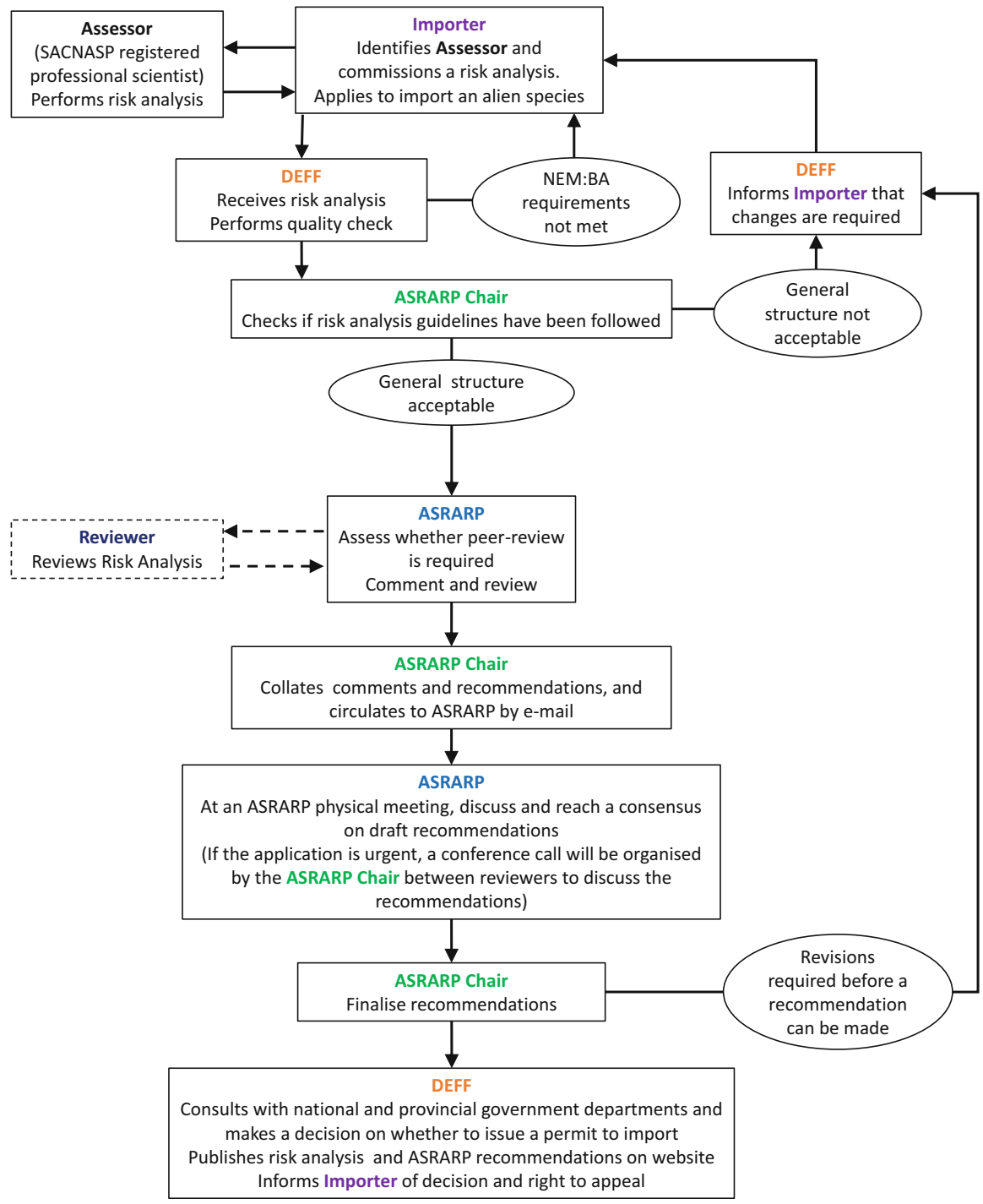

Fig. 20.4 Procedure for development of recommendations regarding the import of an alien species not currently legally in the country, specifically focusing on the review of applications by the Alien Species Risk Analysis Review Panel (ASRARP). Acronyms: SACNASP South African Council of Natural Science Practitioners, DEFF Department of Environment, Forestry and Fisheries, NEM:BA National Environmental Management: Biodiversity Act 2004 (Act No. 10 of 2004) Alien and Invasive Species Regulations, 2014 


\subsubsection{Listing of Alien Species Under National Legislation}

There are two broad types of regulatory lists in South Africa, namely the prohibited list, which consists of species not yet present in the country, and a list of species which are in the country and need to be managed to reduce their impacts. The latter puts species in categories based on the benefits and the feasibility of control, namely: Category 1aeradication targets; Category $1 \mathrm{~b}$ — control targets needing a national management plan; Category 2-species requiring a permit for restricted activities (1b outside of permitted conditions - see next section for details); Category 3-species which can remain but need to be phased out (propagation to be prevented). The initial development of the lists of species regulated under national legislation included workshops with taxonomic experts to determine which species should be regulated and how (prohibited, or listed for control). Such workshops that include several experts can be very useful as they can reduce biases that could arise if a single expert was used (Sutherland and Burgman 2015). The inclusion of various stakeholders in these meetings was aimed at reducing conflicts and ensuring that stakeholders' voices are heard. However, in this case, decisions on which species and taxa to list were not based on a structured or transparent process, as no consistent framework for risk analysis was available. Each taxon-specific working group took a slightly different approach to develop recommendations on which species to regulate and how. The final decisions were, of course, taken by policy makers, but it is not clear why (and in some cases how) these decisions differed from the recommendations, as neither process was made publicly available.

Given the lack of transparency of the process leading to the regulation of certain alien taxa in South Africa, stakeholders have raised queries about the species that are regulated. As a result, various retrospective assessments and analyses have been carried out as emergency measures to respond to the criticisms, but none of those followed a framework specifically developed for South African conditions. A framework for decision-making related to the regulation of species needs to consider all aspects of risk and be explicit enough to transparently show the decision-making process and the evidence underpinning it (Roy et al. 2018). The Risk Analysis for Alien Taxa Framework - as described in the previous section-has been developed to this end (Kumschick et al. 2018). Besides the need to assess whether a species is of high risk, management feasibility and benefits of the species need to be assessed to underpin decisions regarding the listing category (Fig. 20.2). The benefits of using such a framework, as opposed to expert opinion alone, are that it leads to more transparent policy which is evidence-based and therefore more defendable. Furthermore, it provides stakeholders with reasons for management implications which should prevent queries from being raised.

\subsubsection{Permits for Restricted Activities}

Restricted activities, as defined in the NEM:BA A\&IS Regulations, include, amongst others, possession, breeding, propagating or trading of listed alien species. Some alien species can be extremely harmful to the recipient environment, but at the 
same time have large benefits for some stakeholders. Such species are generally termed "conflict species" as they often lead to disputes around their management and control (Zengeya et al. 2017). On the one hand, once there is a large enough market for a species it is often difficult to enforce control. On the other hand, in many cases some of the impacts can be avoided and risks mitigated with risk management strategies. For example, keeping pets in escape-safe cages can ensure they do not get introduced into natural areas and cause harm to native species. Similarly, importing only males of certain species can (in most cases) prevent propagation and therefore the establishment of the species in the new area, even should some individuals escape. This issue is tackled with the requirement of permits for certain species (Category 2 listed species under the NEM:BA A\&IS Regulations in South Africa; although permits to conduct research or biological control tests can be issued for work on taxa listed in other categories) and the development of permit conditions that mitigate the risks of the species. Each species regulated under national legislation would have gone through a thorough risk analysis process in order to be listed (see above). Therefore permit applications for restricted activities for some species mainly focus on risk management aspects including, for example, the nature and location of the planned activity and the number and sex of individuals to be used. This is similar to requirements for import permits for new alien species (see above). These considerations should be detailed enough to cover risk related to any of the activities involved, including for example transport from breeding facilities elsewhere. Permits already issued and refused for species listed as Category 2 under the NEM:BA A\&IS Regulations in South Africa are listed in Table 20.2.

\subsubsection{Non-regulated Alien Species}

Various other activities would benefit from having frameworks and processes in place to prevent unintended negative consequences. This includes for example the commercialisation of alien species present in the country but not (yet) regulated under national legislation. At present, such species can be cultivated and traded without restrictions under the NEM:BA A\&IS Regulations (although they are subject to other regulations like the Convention on International Trade in Endangered Species of Wild Fauna and Flora, CITES). Given that propagule pressure plays an important role in the establishment success of species, certain uses could enhance the chances of some species becoming invasive and causing harm (e.g. Kumschick et al. 2016). An example in South Africa to illustrate the potential issue is the "giant flag" project (www.giantflag.co.za), to build a South African flag consisting of colourful desert plants (including alien cacti). The alien cacti initially proposed to be used for this project were not considered as a particularly high risk in South Africa by the project co-ordinator, partly because of their main use as horticultural species and the low propagule pressure related to their use. However, the proposed project involves the planting of millions of cacti in their preferred habitat in South Africa, which changes the risk of these species becoming invasive due to the sheer number of individuals planted (Colautti et al. 2006). 


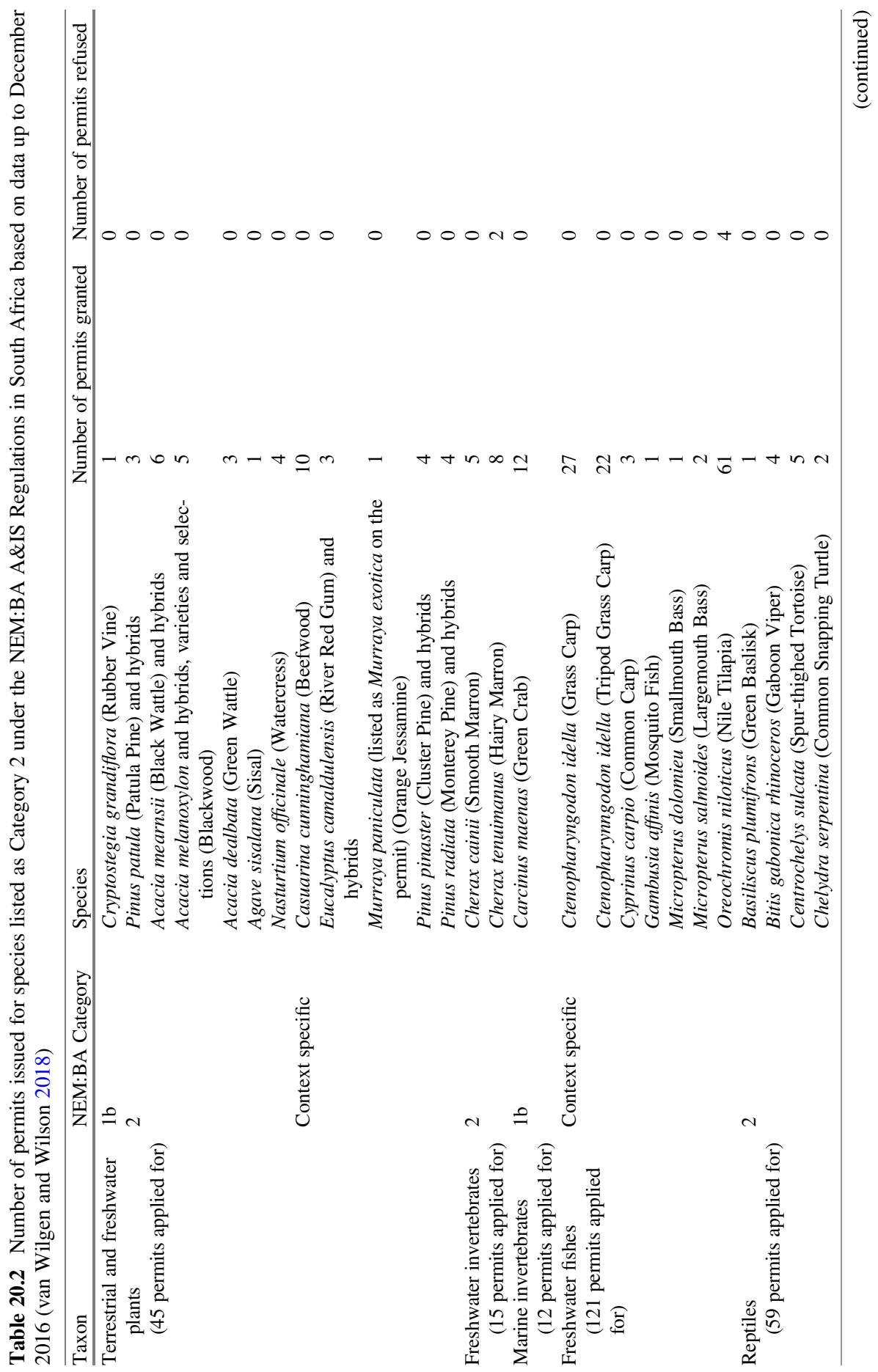




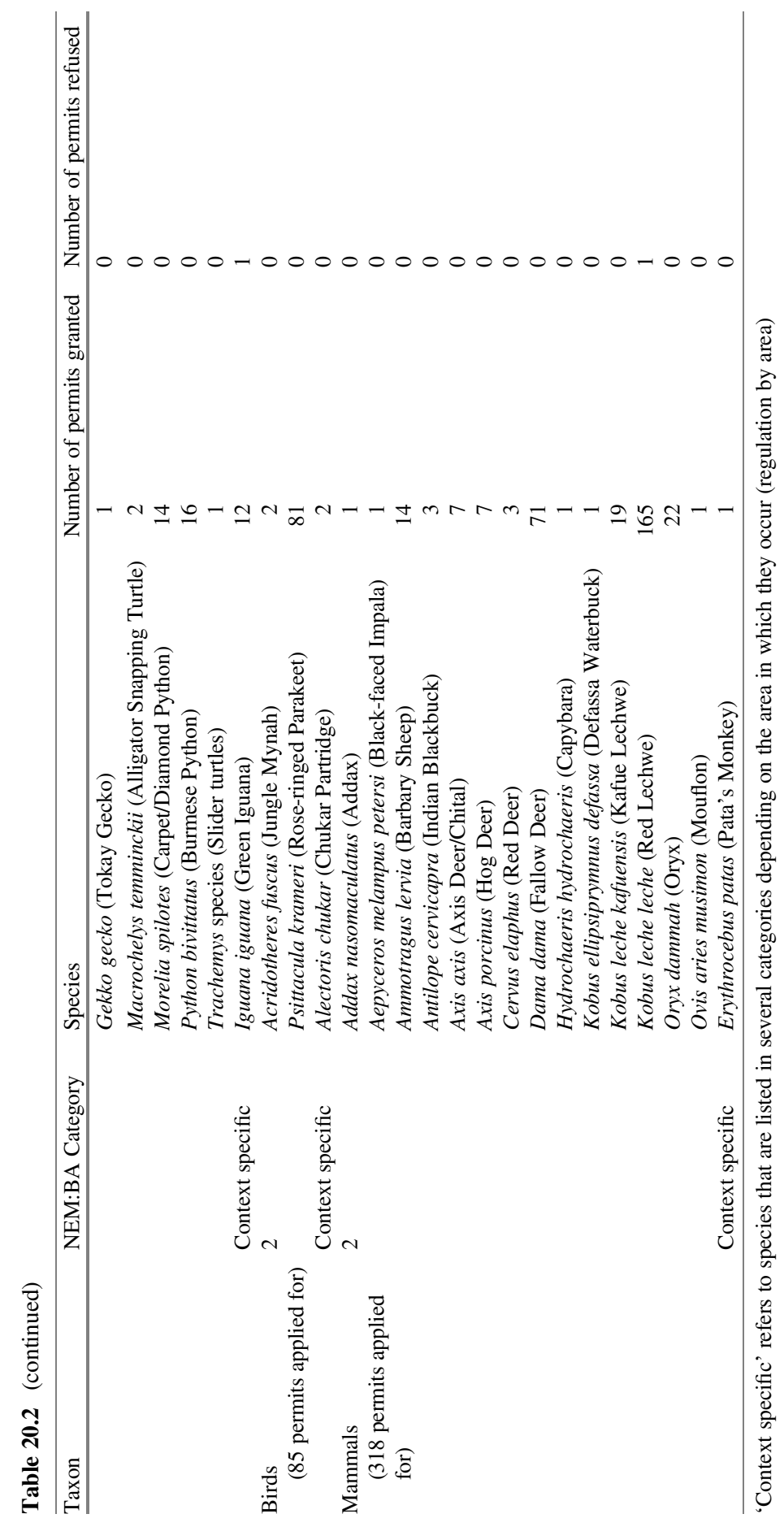




\subsubsection{Release Applications for Biological Control Agents}

A separate process to ensure that the introduction and release of classical biological agents for alien plants poses an acceptable environmental risk has been highly efficient (Moran et al. 2005). The levels of risk and protocols followed are based on international best practice, and largely determined by the research community itself. As a result, the process for assessing risks of the deliberate release of biological control agents against various invasive alien plants is very sophisticated and includes the collection of new data and conducting of experiments under quarantine over several years (Klein et al. 2011; for more information on biological control, see Hill et al. 2020, Chap. 19). These experiments include host-specificity tests to make sure the agent only feeds on or attacks the target species to be controlled and no other, closely related native plants and crops. All these experiments take place in secure quarantine facilities which reduces the risk of unintentional release of the species under investigation and allows for the screening of parasites and pathogens on the potential agent. Permit applications for the release of biological control agents, including an estimate of the likelihood and consequences of non-target effects and an assessment on the potential benefits of the introduction, are compiled by a dedicated team of scientists and submitted to the decision making body (in this case chaired by DALRRD). The applications including the risk assessments are then reviewed by an independent panel of experts similar to ASRARP, namely the National Biological Control Release Application Review Committee (Zachariades et al. 2017), and sent for review to international experts. The record of safety is enviable. Despite South Africa being among the top five countries globally with regard to the use of weed biological control, no direct significant non-target effects of weed biological control agents in South Africa have been detected over the past century (Moran et al. 2005).

\subsection{Conclusions}

South Africa's environment and biodiversity need to be protected from the negative impacts of biological invasions (see Le Maitre et al. 2020, Chap. 15; O'Connor and van Wilgen 2020, Chap. 16; Zengeya et al. 2020, Chap. 17). Risk analysis can aid towards reaching this goal insofar as it can help us distinguish the "good" from the "bad" alien species. Furthermore, there are clear economic benefits that come about by using risk analyses to underpin management decisions on alien species (e.g. Keller et al. 2007). This chapter provides guidelines on how to optimise the use of risk analysis to regulate imports and permitting of alien species and to underpin decisions regarding their management.

However, risk analyses have limitations. They can provide important information to prioritise species for management, but risk analyses are not, by themselves, prioritisation tools. Decisions as to which species to manage, and how, depend on 
the funds available, the costs of management, and many other factors that are not addressed in most risk analyses. Risk analyses are also not equivalent to, and cannot replace, management plans. While risk analyses compile much useful information for the management of a species, pathway, or area, additional information is needed and SMART (Specific, Measurable, Achievable, Realistic, and Timely) goals need to be set for management. Furthermore, as mentioned earlier, desktop-based risk analyses cannot replace detailed assessments of the feasibility of eradication (e.g. Kaplan et al. 2012; Jacobs et al. 2014), but they can provide useful information to aid prioritisation of potential eradication targets. South Africa has historically taken a pragmatic or reactive approach to the issue, but we believe that the solutions provided here offer an opportunity for more transparent and evidence-based decision-making.

Acknowledgements We thank Reuben Keller for his work on approaches to risk assessments, Kim Canavan for advice with biological control risk assessments, and Craig Whittington-Jones for a report on provincial processes related to import applications. We also thank the reviewers for helpful comments. The South African Department of Environment, Forestry, and Fisheries (DEFF) are thanked for funding the South African National Biodiversity Institute noting that this publication does not necessarily represent the views or opinions of DEFF or its employees.

\section{References}

Bacher S, Blackburn TM, Essl F et al (2018) Socio-economic impact classification of alien taxa (SEICAT) with data theft. Methods Ecol Evol 9:159-168. https://doi.org/10.1111/2041-210X. 12844

Blackburn TM, Pyšek P, Bacher S et al (2011) A proposed unified framework for biological invasions. Trends Ecol Evol 26:333-339. https://doi.org/10.1016/j.tree.2011.03.023

Blackburn TM, Essl F, Evans T et al (2014) A unified classification of alien species based on the magnitude of their environmental impacts. PLoS Biol 12:e1001850. https://doi.org/10.1371/ journal.pbio. 1001850

Branquart E, D'hondt B, Vanderhoeven S et al (2016) From impact studies to management actions: practicing risk analysis of introduced trees. In: Krumm F, Vitkova L (eds) Introduced tree species in European forests: opportunities and challenges. European Forest Institute, Joensuu, pp 114-125

Colautti RI, Grigorovich IA, MacIsaac HJ (2006) Propagule pressure: a null model for biological invasions. Biol Invasions 8:1023-1037. https://doi.org/10.1007/s10530-005-3735-y

Convention on Biological Diversity (2002) COP 6 decision VI/23. The 6th conference of the parties of the convention on biological diversity decision VI/23, The Hague, 7-19 April 2002. https:// www.cbd.int/decision/cop/?id=7197. Accessed 18 May 2018

Copp GH, Garthwaite R, Gozlan RE (2005) Risk identification and assessment of non-native freshwater fishes: concepts and perspectives on protocols for the UK. Cefas Science Technical Report No. 129. Cefas, Lowestoft. https://doi.org/10.1111/j.1439-0426.2005.00692.x

D'hondt B, Vanderhoeven S, Roelandt S et al (2015) Harmonia+ and Pandora+: risk screening tools for potentially invasive plants, animals, and their pathogens. Biol Invasions 17:1869-1883. https://doi.org/10.1007/s10530-015-0843-1

Department of Environmental Affairs (2014) National Environmental Management: Biodiversity Act 2004 (Act No. 10 of 2004) Alien and Invasive Species Regulations, 2014. Government Gazette 590(37885) 
Ellender BR, Weyl OLF (2014) A review of current knowledge, risk and ecological impacts associated with non-native freshwater fish introductions in South Africa. Aquat Invasions 9:117-132. https://doi.org/10.3391/ai.2014.9.2.01

FAO (1996) Pest risk analysis for quarantine pests. International standards for phytosanitary measures publication no. FAO, Rome, $\mathrm{p} 11$

Faulkner KT, Robertson MP, Rouget M et al (2014) A simple, rapid methodology for developing invasive species watchlists. Biol Conserv 179:25-32. https://doi.org/10.1016/j.biocon.2014.08. 014

Hill MP, Moran VC, Hoffmann JH et al (2020) More than a century of biological control against invasive alien plants in South Africa: a synoptic view of what has been accomplished. In: van Wilgen BW, Measey J, Richardson DM, Wilson JR, Zengeya TA (eds) Biological invasions in South Africa. Springer, Berlin, pp 549-568. https://doi.org/10.1007/978-3-030-32394-3_19

International Maritime Organization (2004) International convention for the control and management of ships' ballast water and sediments, 2004. BWM/CONF/36. IMO, London

IUCN (2000) IUCN guidelines for the prevention of biodiversity loss caused by alien invasive species approved by 51st meeting of the IUCN Council, February 2000. http://www.issg.org/ infpaper_invasive.pdf

Jacobs L, Richardson DM, Wilson JRU (2014) Melaleuca parvistaminea Byrnes (Myrtaceae) in South Africa: invasion risk and feasibility of eradication. S Afr J Bot 94:24-32. https://doi.org/ 10.1016/j.sajb.2014.05.002

Kaplan H, van Zyl HWF, Le Roux JJ et al (2012) Distribution and management of Acacia implexa in South Africa: is eradication an option? S Afr J Bot 83:23-35. https://doi.org/10.1016/j.sajb. 2012.07.016

Keller RP, Kumschick S (2017) Promise and challenges of risk assessment as an approach for preventing the arrival of invasive species. Bothalia 47:131-138. https://doi.org/10.4102/abc. v47i2.2136

Keller RP, Lodge DM, Finnoff DC (2007) Risk assessment for invasive species produces net bioeconomic benefits. Proc Natl Acad Sci USA 104:203-207. https://doi.org/10.1073/pnas. 0605787104

Klein H, Hill MP, Zachariades C et al (2011) Regulation and risk assessment for importations and releases of biological control agents against invasive alien plants in South Africa. Afr Entomol 19:488-497. https://doi.org/10.4001/003.019.0215

Kumschick S, Richardson DM (2013) Species-based risk assessments for biological invasions: advances and challenges. Divers Distrib 19:1095-1105. https://doi.org/10.1111/ddi.12110

Kumschick S, Bacher S, Dawson W et al (2012) A conceptual framework for prioritization of invasive alien species for management according to their impact. NeoBiota 15:69-100. https:// doi.org/10.3897/neobiota. 15.3323

Kumschick S, Devenish A, Kenis M et al (2016) Intentionally introduced terrestrial invertebrates: patterns, risks, and options for management. Biol Invasions 18:1077-1088. https://doi.org/10. 1007/s10530-016-1086-5

Kumschick S, Wilson JR, Foxcroft LC (2018) Framework and guidelines for conducting risk analyses for alien species. Preprints. https://doi.org/10.20944/preprints201811.0551.v1

Le Maitre DC, Blignaut JN, Clulow A et al (2020) Impacts of plant invasions on terrestrial water flows in South Africa. In: van Wilgen BW, Measey J, Richardson DM, Wilson JR, Zengeya TA (eds) Biological invasions in South Africa. Springer, Berlin, pp 429-456. https://doi.org/10. 1007/978-3-030-32394-3_15

Leung B, Roura-Pascual N, Bacher S et al (2012) TEASIng apart alien species risk assessments: a framework for best practices. Ecol Lett 15:1475-1493. https://doi.org/10.1111/ele.12003

Mandrak NE, Cudmore B (2004) Risk assessment for Asian carps in Canada. Department of Fisheries and Oceans Canada. Burlington, Ontario

Marr SM, Ellender BR, Woodford DJ et al (2017) Evaluating invasion risk for freshwater fishes in South Africa. Bothalia 47(2):150-159. https://doi.org/10.4102/abc.v47i2.2177

Montibeller G, Von Winterfeldt D (2015) Cognitive and motivational biases in decision and risk analysis. Risk Anal 35(7):1230-1251. https://doi.org/10.1111/risa.12360 
Moran VC, Hoffmann JH, Zimmermann HG (2005) Biological control of invasive alien plants in South Africa: necessity, circumspection, and success. Front Ecol Environ 3:77-83. https://doi. org $/ 10.2307 / 3868513$

Nentwig W, Bacher S, Pyšek P, Vilà M, Kumschick S (2016) The generic impact scoring system (GISS): a standardized tool to quantify the impacts of alien species. Environ Monit Assess 188:315. https://doi.org/10.1007/s10661-016-5321-4

Novoa A, Kaplan H, Kumschick S et al (2015) Soft touch or heavy hand? Legislative approaches for preventing invasions: insights from Cactaceae in South Africa. Invasive Plant Sci Manag 8:307-316. https://doi.org/10.1614/IPSM-D-14-00073.1

Novoa A, Kumschick S, Richardson DM et al (2016a) Native range size and growth form in Cactaceae predicts invasiveness and impact. NeoBiota 30:75-90. https://doi.org/10.3897/ neobiota. 30.7253

Novoa A, Kaplan H, Wilson JRU et al (2016b) Resolving a prickly situation: involving stakeholders in invasive cactus management in South Africa. Environ Manag 57:998-1008. https:// doi.org/10.1007/s00267-015-0645-3

O'Connor T, van Wilgen BW (2020) The impact of invasive alien plants on rangelands in South Africa. In: van Wilgen BW, Measey J, Richardson DM, Wilson JR, Zengeya TA (eds) Biological invasions in South Africa. Springer, Berlin, pp 457-486. https://doi.org/10.1007/ 978-3-030-32394-3_16

OIE (2011) Guidelines for assessing the risk of non-native animals becoming invasive. http://www. oie.int/fileadmin/Home/eng/Our_scientific_expertise/docs/pdf/OIEGuidelines_

NonNativeAnimals_2012.pdf. Accessed 30 Aug 2017

Panetta FD, Timmins SM (2004) Evaluating the feasibility of eradication for terrestrial weed invasions. Plant Prot Q 19:5-11

Pheloung PC, Williams PA, Halloy SR (1999) A weed risk assessment model for use as a biosecurity tool evaluating plant introductions. J Environ Manag 57:239-251. https://doi.org/ 10.1006/jema.1999.0297

Renteria JL, Rouget M, Visser V (2017) Rapid prioritisation of alien plants for eradication based on climatic suitability and eradication feasibility. Austral Ecol 42:995-1005. https://doi.org/10. 1111/aec. 12528

Richardson DM, Le Roux JJ, Wilson JRU (2015) Australian acacias as invasive species: lessons to be learnt from regions with long planting histories. South For 77:31-39. https://doi.org/10.2989/ 20702620.2014.999305

Roy HE, Rabitsch W, Scalera R et al (2018) Developing a framework of minimum standards for the risk assessment of alien species. J Appl Ecol 55(2):526-538. https://doi.org/10.1111/13652664.13025

Scholes RJ, Schreiner GO, Snyman-van der Walt L (2017) Scientific assessments: matching the process to the problem. Bothalia 47:191-199. https://doi.org/10.4102/abc.v47i2.2144

Shackleton RT, Novoa A, Shackleton CM et al (2020) The social dimensions of biological invasions in South Africa In: van Wilgen BW, Measey J, Richardson DM, Wilson JR, Zengeya TA (eds) Biological invasions in South Africa. Springer, Berlin, pp 697-726. https://doi.org/10. 1007/978-3-030-32394-3_24

Soliman T, MacLeod A, Mumford JD et al (2016) A regional decision support scheme for pest risk analysis in Southeast Asia. Risk Anal 36(5):904-913. https://doi.org/10.1111/risa.12477

Sutherland WJ, Burgman MA (2015) Use experts wisely. Nature 526(7573):317-318. https://doi. org/10.1038/526317a

Tricarico E, Vilizzi L, Gherardi F et al (2010) Calibration of FI-ISK, an invasiveness screening tool for nonnative freshwater invertebrates. Risk Anal 30:285-292. https://doi.org/10.1111/j.15396924.2009.01255.x

Tucker KC, Richardson DM (1995) An expert system for screening potentially invasive alien plants in South African Fynbos. J Environ Manag 44:309-338. https://doi.org/10.1016/S0301-4797 (95) $90347-X$

van Wilgen BW, Richardson DM (2012) Three centuries of managing introduced conifers in South Africa: benefits, impacts, changing perceptions and conflict resolution. J Environ Manag 106:56-68. https://doi.org/10.1016/j.jenvman.2012.03.052 
van Wilgen BW, Wilson JR (2018) The status of biological invasions and their management in South Africa in 2017. South African National Biodiversity Institute, Kirstenbosch and DST-NRF Centre of Excellence for Invasion Biology, Stellenbosch

van Wilgen NJ, Richardson DM, Baard EHW (2008) Alien reptiles and amphibians in South Africa: towards a pragmatic management strategy. S Afr J Sci 104:13-20

van Wilgen NJ, Roura-Pascual N, Richardson DM (2009) A quantitative climate-match score for risk-assessment screening of reptile and amphibian introductions. Environ Manag 44:590-607. https://doi.org/10.1007/s00267-009-9311-y

van Wilgen BW, Measey J, Richardson DM et al (2020) Biological invasions in South Africa: an overview. In: van Wilgen BW, Measey J, Richardson DM, Wilson JR, Zengeya TA (eds) Biological invasions in South Africa. Springer, Berlin, pp 3-30. https://doi.org/10.1007/978-3030-32394-3_1

Weyl OLF, Ellender B, Wassermann RJ et al (2020) Alien freshwater fauna in South Africa. In: van Wilgen BW, Measey J, Richardson DM, Wilson JR, Zengeya TA (eds) Biological invasions in South Africa. Springer, Berlin, pp 151-182. https://doi.org/10.1007/978-3-030-32394-3_6

Wilson JRU, Gairifo C, Gibson MR et al (2011) Risk assessment, eradication, and biological control: global efforts to limit Australian acacia invasions. Divers Distrib 17:1030-1046. https:// doi.org/10.1111/j.1472-4642.2011.00815.x

Wilson JR, Panetta FD, Lindgren C (2017) Detecting and responding to alien plant incursions. Cambridge University Press, Cambridge. https://doi.org/10.1017/CBO9781316155318

Wilson JR, Foxcroft LC, Geerts S et al (2020) The role of environmental factors in promoting and limiting biological invasions in South Africa. In: van Wilgen BW, Measey J, Richardson DM, Wilson JR, Zengeya TA (eds) Biological invasions in South Africa. Springer, Berlin, pp 353-384. https://doi.org/10.1007/978-3-030-32394-3_13

Woodford DJ, Richardson DM, MacIsaac HJ et al (2016) Confronting the wicked problem of managing biological invasions. NeoBiota 31:63-86. https://doi.org/10.3897/neobiota.31.10038

Woodford DJ, Ivey P, Jordaan MS et al (2017) Optimising invasive fish management in the context of invasive species legislation in South Africa. Bothalia 47:245-253. https://doi.org/10.4102/ abc.v47i2.2138

Zachariades C, Paterson ID, Strathie LW et al (2017) Assessing the status of biological control as a management tool for suppression of invasive alien plants in South Africa. Bothalia 47:254-272. https://doi.org/10.4102/abc.v47i2.2142

Zengeya T, Ivey P, Woodford DJ et al (2017) Managing conflict-generating invasive species in South Africa: challenges and trade-offs. Bothalia 47:273-283. https://doi.org/10.4102/abc. v47i2.2160

Zengeya TA, Kumschick S, Weyl OLF et al (2020) An evaluation of the impacts of alien species on biodiversity in South Africa using different assessment methods. In: van Wilgen BW, Measey J, Richardson DM, Wilson JR, Zengeya TA (eds) Biological invasions in South Africa. Springer, Berlin, pp 487-512. https://doi.org/10.1007/978-3-030-32394-3_17

Open Access This chapter is licensed under the terms of the Creative Commons Attribution 4.0 International License (http://creativecommons.org/licenses/by/4.0/), which permits use, sharing, adaptation, distribution and reproduction in any medium or format, as long as you give appropriate credit to the original author(s) and the source, provide a link to the Creative Commons licence and indicate if changes were made.

The images or other third party material in this chapter are included in the chapter's Creative Commons licence, unless indicated otherwise in a credit line to the material. If material is not included in the chapter's Creative Commons licence and your intended use is not permitted by statutory regulation or exceeds the permitted use, you will need to obtain permission directly from the copyright holder.

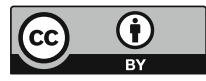

